\title{
Effects of Paper Mulberry (Broussonetia papyrifera) Leaf Extract on Growth Performance and Fecal Microflora of Weaned Piglets
}

\author{
Guoshun Chen $\mathbb{D}^{1},{ }^{1}$ Shengzhang Shui, ${ }^{1}$ Mingjie Chai, ${ }^{1}$ Dong Wang, ${ }^{1}$ Yingyu Su, ${ }^{1}$ \\ Hongbin $\mathrm{Wu},{ }^{1}$ Xiaodong Sui, ${ }^{2}$ and Yulong Yin $^{3}$ \\ ${ }^{1}$ College of Animal Science and Technology, Gansu Agricultural University, Lanzhou, 730070 Gansu, China \\ ${ }^{2}$ Gansu Aonong Feed Technology Co., Ltd., Wuwei, 733000 Gansu, China \\ ${ }^{3}$ The Institute of Subtropical Agriculture, The Chinese Academy of Sciences, Changsha, 410000 Hunan, China
}

Correspondence should be addressed to Guoshun Chen; chengs@gsau.edu.cn

Received 13 June 2020; Revised 14 October 2020; Accepted 5 November 2020; Published 18 November 2020

Academic Editor: Swaran J. S. Flora

Copyright ( 2020 Guoshun Chen et al. This is an open access article distributed under the Creative Commons Attribution License, which permits unrestricted use, distribution, and reproduction in any medium, provided the original work is properly cited.

\begin{abstract}
The paper mulberry (Broussonetia papyrifera) leaf is rich in alkaloids and flavonoids, which has high medicinal and feeding value. We aimed to analyze the effects of $B$. papyrifera leaf extract on growth performance, antioxidant capacity, immune functions, and fecal microflora of weaned piglets. Thirty healthy, 28-day-old piglets were randomly assigned to three groups and fed with a basal diet supplemented with 0,150 , and $300 \mathrm{~g} / \mathrm{t}$ B. papyrifera leaf extract for 42 days (control group, group I, and group II) separately. The result revealed that the final weight of piglets in group II was higher than the other groups, and the diarrhea rate in this group was $62.9 \%$ lower than in the control group. The feed conversion ratio in group I was significantly lower than the other two groups. Higher blood urine nitrogen concentration was noted in group II, higher glutathione peroxidase and catalase in group II, higher superoxide dismutase in the control group, and higher immune globulins (Ig) IgG, IgA, and IgM in group II. There was no significant difference in community richness and community diversity among the three groups of fecal samples. The relative level of Roseburia was higher in groups I and II, while Lactobacillus was higher in the control group. In conclusion, supplementation with $B$. papyrifera leaf extract at a certain dosage can increase growth performance and antioxidant capacity of weaned piglets, reduce the occurrence of diarrhea, enhance immune functions and disease resistance, and affect the composition of fecal microflora.
\end{abstract}

\section{Introduction}

The term feed additives generally refer to ingredients that are intentionally added to animal feed to improve palatability, promote growth, and increase decomposition of antinutritional components $[1,2]$. Numerous chemical feed additives are used for animal feed. Unfortunately, most of them have been proven to be harmful to animals or may produce antibiotic residues [3]. In recent years, because of increasing awareness of antibiotic resistances and residues of antibiotics in animal products, the potential risks of such antibiotic residues and trends toward more natural products have led to regulations prohibiting the use of antibiotics as feed additives [4].

Plant extract-based feed additives, one of the important alternatives to conventional antibiotics, are attracting increasing interest in animal feed production and production animal farming. There are about 250,000 to 500,000 plant species on Earth; however, only a small fraction (1\%-10\%) is used for human nutrition or for animal feed production and other purposes [5]. Natural plant extracts are typically processed to isolate active ingredients which are then used for feed production. The original plant material may contain a plethora of different chemical compounds which may play a critical role in animal feed. The main role of plant extracts in animal nutrition is to promote appetence, improve digestion, increase lactation, and prevent or treat certain diseases $[6,7]$.

The paper mulberry (Broussonetia papyrifera) is a deciduous tree belonging to the mulberry family (Moraceae) [8]. In Chinese medical research, numerous beneficial effects of B. papyrifera leaves have been identified, including 
antibacterial and antitumor effects, reducing blood sugar, enhancing immunity, and delaying the aging; these leaves are also commonly used as supplements in farm animal feed [9]. Fresh leaves of B. papyrifera are difficult to digest; thus, leaves are typically fermented by microbial degradation to increase digestibility [10]. However, fresh and fermented leaves may cause problems associated with cellulose digestion; therefore, the added amount must not exceed a certain threshold, which limits its applicability as a feed additive. It has been reported that supplementation with $15 \%$ B. papyrifera silage in the diet could improve the body weight, dry matter intake, and feed conversion rate of cattle [11]. The good adding effect in cattle feed may be explained by the fact that cattle belong to ruminants and can digest cellulose well. Thus, it may be more effective to extract the active components from $B$. papyrifera as feed additives for pigs. The main active ingredients in $B$. papyrifera leaves are flavonoids and alkaloids $[12,13]$. The flavonoids mainly include quercetin, isoglycyrrhizin, and carotenoids. Flavonoids are polyphenolic metabolites of various plants and occur commonly in fruit, grains, and vegetables [14]. At present, more than 10,000 natural flavonoids have been identified, and these compounds have become important components of various nutrients, cosmetics, and pharmaceuticals [15]. Their main functions include antioxidative, anti-inflammatory, and anticancer activities [16]. Alkaloids are typically basic nitrogencontaining compounds that occur in living organisms that are generally associated with crucial physiological activities [17]. In animal breeding, some related plant extract products have been used that can reduce the number of bacterial colonies in poultry and pigs, reduce intestinal fermentation and intestinal-related lymphatic system activity, and promote intestinal mucus production [18]. Thus, the objective of the present study was to investigate effects of $B$. papyrifera extract on growth performance and fecal microflora of weaned piglets to identify an optimized supplementation regime for rearing weaned piglets.

\section{Material and Methods}

2.1. Experimental Design and Study Animals. A total of 30 weaned piglets (Duroc $\times$ Landrace $\times$ Yorkshire; $7.18 \pm 0.33$ $\mathrm{kg}$ body weight) were randomly assigned to three groups of 10 individuals, each. Piglets were weaned 28 days after birth and were then fed pellets. Piglets in the control group were fed a basal diet (Table 1), group I was fed the basal diet supplemented with $150 \mathrm{~g} / \mathrm{t}$ B. papyrifera leaf extract (containing alkaloids and flavonoids), and group II was fed the basal diet supplemented with $300 \mathrm{~g} / \mathrm{t}$ B. papyrifera leaf extract. Feeding regime and environmental conditions were otherwise consistent between groups. Each group was fed at 6:00 a.m., 8:30 a.m., 12:00 p.m., 2:30 p.m., and 5:00 p.m. every day, and water was provided ad libitum. The barn and the pens were cleaned and disinfected on a daily basis to prevent diseases.

A total of $8500 \mathrm{~g}$ fresh B. papyrifera leaves were ground to extract active ingredients. Ground leaves were placed in a water bath at approximately $50-60^{\circ} \mathrm{C}$, and three consecutive extractions were performed using $75 \%$ ethanol. The ratio of $75 \%$ ethanol to B. papyrifera leaves was 30:1 (volume: mass).
TABle 1: Composition of the basal diets (\%).

\begin{tabular}{lc}
\hline Item & Inclusion level \\
\hline Maize & 33.00 \\
Soybean meal (46\%) & 10.00 \\
Fish meal & 3.00 \\
Fermented soybean meal & 5.00 \\
Puffed soybean & 6.00 \\
Puffed maize & 26.00 \\
Whey powder & 3.00 \\
Salt & 0.20 \\
Calcium hydrogen phosphate & 1.20 \\
Stone powder & 1.00 \\
Suckling premix nutrient (1\%) ${ }^{\mathrm{a}}$ & 1.00 \\
Rapeseed oil & 1.00 \\
Wheat middlings & 5.00 \\
Wheat bran & 3.40 \\
Porcine compound enzyme & 0.10 \\
Flavouring agent & 0.03 \\
Sweetener agent & 0.02 \\
Montmorillonite & 0.20 \\
Acidifier & 0.40 \\
Threonine & 0.10 \\
Lysine & 0.20 \\
Methionine & 0.10 \\
Choline (VB450\%) & 0.05 \\
Digestive energy & 13.81 \\
Crude protein & 17.80 \\
Total phosphorus & 0.65 \\
Effective phosphorus & 0.54 \\
Sodium chloride & 0.36 \\
Sucking premix nutient & 0.20 \\
\hline
\end{tabular}

${ }^{a}$ Suckling premix nutrient (1\%) content is equivalent to each kilogram of compound feed (not less than): Fe $75.0 \mathrm{mg}$; Zn $65.0 \mathrm{mg}$; Mn $18.0 \mathrm{mg} ; \mathrm{Cu}$ $5.0 \mathrm{mg}$; Se $0.3 \mathrm{mg}$, I $0.14 \mathrm{mg}$; VA $3200 \mathrm{IU} ;$ VD $450 \mathrm{IU} ; \mathrm{VE} 68.0 \mathrm{mg}$; thiamine $2.15 \mathrm{mg}$; riboflavin $2.80 \mathrm{mg}$; biotin $0.25 \mathrm{mg}$; folic acid $0.66 \mathrm{mg}$; niacin $32.00 \mathrm{mg}$; thbrthdrexvbdr $12.00 \mathrm{mg} ; \mathrm{VB}_{6} 1.10 \mathrm{mg} ; \mathrm{VB}_{12} 0.02 \mathrm{mg}$; choline chloride $450.00 \mathrm{mg}$; and antioxidants $30.00 \mathrm{mg}$.

The $1500 \mathrm{~g}$ produced extracts were pooled and were diluted with $1200 \mathrm{~mL} 50-60^{\circ} \mathrm{C}$ water. This solution was then extracted using $7500 \mathrm{~mL}$ petroleum ether three times to remove fat-soluble compounds and pigments. Finally, the extract solution was concentrated under reduced pressure and dried in vacuum to obtain $300-380 \mathrm{~g}$ final extract.

\subsection{Growth Performance and Measurement of Biochemical Indicators, Antioxidant Capacity, and Antibody Concentrations. The piglets' body weight was measured at age $28,35,42,49,63$, and 70 days. Occurrences of diarrhea were recorded, and rates were calculated according to the fol- lowing equation: diarrhea rate $=\Sigma$ (the number of piglets with diarrhea $\times$ days on which diarrhea was observed $) /($ number of piglets in the respective treatment $\times$ days of the experimental period) $\times 100$ [19]}


Venous blood $(20 \mathrm{~mL})$ was collected at the age of 70 days. Heparin sodium was added to $10 \mathrm{~mL}$ of venous blood to separate plasma at $25^{\circ} \mathrm{C}$ for $30 \mathrm{~min}$. An additional $10 \mathrm{~mL}$ of venous blood was centrifugated at $25^{\circ} \mathrm{C}$ for $30 \mathrm{~min}$ to separate serum. ELISA kits (Shanghai Jianglai Biological Technology Co., Ltd., Shanghai, China) were used to determine activity of alanine aminotransferase (ALT), alkaline phosphatase (ALP), total superoxide dismutase (SOD), glutathione peroxidase (GSH-Px), and catalase (CAT) and to determine the serum content of total protein (TP), albumin (ALB), globulin (GLB), glucose (GLU), malondialdehyde (MDA), and blood urine nitrogen (BUN). Serum concentrations of immune globulins (Ig) IgG, IgA, and IgM and total antioxidant capacity (T-AOC) were also determined using the ELISA kit.

2.3. $16 \mathrm{~S}$ rDNA Sequencing and Analysis. At the age of 63 days, three healthy piglets were selected from each group, and their feces were collected in sterile containers that were then stored in liquid nitrogen. DNA was isolated from feces using a QIAamp DNA Stool Mini Kit (QIAGEN, Germany). Bacterial 16S rDNA amplicons of the variable region V4 were produced using specific PCR primers (515FGTGNCAGCMGCCGCGGTAA and 806R-GGAC TACNVGGGTWTCTAA).

Sequencing libraries were constructed by using a TruSeq DNA PCR-Free sample preparation kit (Illumina, San Diego, CA, USA) followed by quality evaluation using a Qubit 2.0 device. The libraries were sequenced on an Illumina HiSeq 2500 platform using a HiSeq Rapid SBS Kit v2 with 500 cycles. Raw tags were obtained by merging paired-end reads using the FLASH (v1.2.7, http://ccb.jhu .edu/software/FLASH/) software. Chimera sequences were removed to select effective tags from clean tags. Operational taxonomic units (OTUs) were produced by clustering tags using a similarity threshold level. Taxonomic annotations of OTUs were produced using the Silva software (http://www.arb-silva.de) and the UNITE database (http://unite.ut.ee/index.php). Richness and diversity analyses were conducted based on alpha diversity which was evaluated using the $\mathrm{R}$ software with the four indicators Chaol, Ace, Shannon, and Simpson. The QIIME software was used to test beta diversity and to compare similarity between different samples.

2.4. Statistical Analyses. Data are shown as the mean \pm standard deviation. Data were analyzed with a one-way ANOVA using SPSS 21.0 (SPSS Inc., Chicago, IL, USA). Duncan's multiple comparison test was also used. Differences between treatments were considered significant at $P<0.05$.

\section{Results}

3.1. Growth Performance and Occurrences of Diarrhea. Body weight of piglets in the three groups is shown in Table 2. On days $35(P=0.843)$ and $63(P=0.354)$, no significant difference in body weight was observed between groups I and II. At the end of the experiment, the body weight of piglets in groups I and II was significantly higher than that of piglets in the control group $(P=0.006)$. Diarrhea rate was significantly less common in group II than in the control group and in group I $(P=0.003)$. Average daily feed intake $(P=0.035)$ and feed conversion ratio $(P=0.047)$ of piglets in groups I and II were significantly lower than those of piglets in the control group, and the average daily feed intake of piglets in group II was lowest, with $4.98 \mathrm{~kg}$. The result indicated that piglets supplemented with $300 \mathrm{~g} / \mathrm{t}$ B. papyrifera extract had a better growth performance.

\subsection{Blood Metabolites, Antioxidant, and Immune Functions.} Blood metabolites and immune parameters reflect health status of animals and the utilization of nutrients. No significant differences in TP, ALB, and ALP were observed between the three groups $(P>0.05$; Table 3$)$. Serum levels of ALT, GLU, and GLB did not differ significantly between the control group and group II $(P>0.05)$. Serum levels of ALT and GLU in group I were significantly lower than those in the control group, by $36.47 \% \quad(P=0.042)$ and $43.14 \%$ $(P=0.038)$, respectively. The mean BUN concentration in group II was $8.83 \mathrm{mmol} / \mathrm{L}$, which was significantly higher than that in the control group and group I $(P=0.023)$. The supplementation treatment thus affected serum biochemical characteristics in weaned piglets, which may also influence growth performance and health.

SOD activity was significantly higher in the control group than in groups I and II $(P=0.038)$, and serum GSH-Px $(P=0.046)$ and CAT $(P=0.033)$ activities were significantly higher in group II than in the control group.

Dietary supplementation with $B$. papyrifera can significantly increase IgA concentrations in weaned piglets. IgA $(P=0.036), \operatorname{IgG}(P=0.024)$, and $\operatorname{IgM}(P=0.029)$ concentrations were highest in group II, with $2313.67 \mu \mathrm{g} / \mathrm{mL}$, $9528.00 \mathrm{mg} / \mathrm{L}$, and $1326 \mathrm{mg} / \mathrm{L}$, respectively. The result indicated that the addition of $B$. papyrifera leaf extract had certain effects on blood metabolism, antioxidant, and immune functions of piglets.

3.3. Sequencing Data. A total of 720,482 reads were retrieved from nine samples. All reads were spliced, and 614,299 clean tags were obtained. A minimum of 65,482 clean tags were produced per sample (Supplementary 1). Sequences were grouped as OTUs of a similarity above $97 \%$. Supplementary 2 shows the number of effective tags of the samples and the number of OTUs obtained by clustering each sample. Numbers of clean tags ranged from 44,597 to 52,501 after quality filtering. A total of 512 OTUs were shared by the three treatment groups, and 34,15 , and 14 OTUs were unique to the control group, group I, and group II, respectively (Figures 1(a) and 1(b)).

3.4. Bacterial Diversities and Community Compositions. The top-10 maximum abundance of taxa per each group at the phylum level is shown in Figure 2(a). Firmicutes occurred at the highest relative abundance in all nine samples, followed by Bacteroidetes, Actinobacteria, and Tenericutes. In groups I and II, the proportion of Firmicutes and Proteobacteria was lower and that of Bacteroidetes 
TABLe 2: Performance of piglets on experimental diets.

\begin{tabular}{|c|c|c|c|c|}
\hline Item & Control & Group I & Group II & $P$ value \\
\hline Initial weight (kg, $28 \mathrm{~d}$ weight) & $7.25 \pm 0.34$ & $7.13 \pm 0.30$ & $7.16 \pm 0.34$ & 0.173 \\
\hline $35 \mathrm{~d}$ weight $(\mathrm{kg})$ & $9.27 \pm 0.63$ & $9.04 \pm 0.75$ & $9.31 \pm 0.34$ & 0.843 \\
\hline $42 \mathrm{~d}$ weight $(\mathrm{kg})$ & $12.03^{\mathrm{A}} \pm 0.73$ & $11.14^{\mathrm{B}} \pm 1.76$ & $12.12^{\mathrm{A}} \pm 0.34$ & 0.004 \\
\hline $49 \mathrm{~d}$ weight $(\mathrm{kg})$ & $15.74^{\mathrm{A}} \pm 0.34$ & $15.30^{\mathrm{B}} \pm 0.75$ & $15.62^{\mathrm{A}} \pm 0.34$ & 0.002 \\
\hline $56 \mathrm{~d}$ weight $(\mathrm{kg})$ & $19.35^{\mathrm{a}} \pm 0.80$ & $19.14^{\mathrm{b}} \pm 0.99$ & $19.59^{\mathrm{a}} \pm 0.35$ & 0.023 \\
\hline $63 \mathrm{~d}$ weight $(\mathrm{kg})$ & $23.94 \pm 0.34$ & $23.62 \pm 0.62$ & $23.82 \pm 0.34$ & 0.354 \\
\hline Final weight (kg, $70 \mathrm{~d}$ weight) & $27.92^{\mathrm{B}} \pm 0.35$ & $28.33^{\mathrm{A}} \pm 0.49$ & $28.52^{\mathrm{A}} \pm 0.34$ & 0.006 \\
\hline Average daily gain (kg/day) & $0.49 \pm 0.01$ & $0.50 \pm 0.01$ & $0.51 \pm 0.01$ & 0.478 \\
\hline Diarrhea rate & $10.00^{C} \pm 0.45$ & $7.70^{\mathrm{B}} \pm 0.51$ & $3.71^{\mathrm{A}} \pm 0.87$ & 0.003 \\
\hline Feed intake (kg/day) & $6.50 \pm 0.26^{c}$ & $5.60 \pm 0.29^{b}$ & $4.98 \pm 0.23^{\mathrm{a}}$ & 0.035 \\
\hline Feed conversion ratio & $13.27 \pm 0.45^{\mathrm{c}}$ & $11.2 \pm 0.48^{\mathrm{b}}$ & $9.76 \pm 0.43^{\mathrm{a}}$ & 0.047 \\
\hline
\end{tabular}

Note: different lowercase letters in the same row represent significant difference $(P<0.05)$; different uppercase letters in the same row represent significant difference $(P<0.01)$; data with the same letter or no letter indicate that the difference was not significant $(P>0.05)$.

TABLE 3: Indicators of piglets on experimental diets.

\begin{tabular}{|c|c|c|c|c|}
\hline Item & Control & Group I & Group II & $P$ value \\
\hline \multicolumn{5}{|c|}{ Plasma biochemical index } \\
\hline $\operatorname{ALT}(\mathrm{U} / \mathrm{L})$ & $57.66^{\mathrm{a}} \pm 5.85$ & $36.63^{\mathrm{b}} \pm 5.16$ & $53.91^{\mathrm{a}} \pm 5.09$ & 0.042 \\
\hline BUN (mmol/L) & $5.67^{\mathrm{b}} \pm 0.86$ & $6.32^{b} \pm 0.63$ & $8.83^{\mathrm{a}} \pm 0.92$ & 0.023 \\
\hline GLU (mmol/L) & $6.63^{\mathrm{a}} \pm 0.47$ & $3.77^{\mathrm{b}} \pm 0.37$ & $5.97^{\mathrm{a}} \pm 0.27$ & 0.038 \\
\hline $\mathrm{TP}(\mathrm{g} / \mathrm{L})$ & $50.92 \pm 3.60$ & $47.49 \pm 2.54$ & $46.72 \pm 3.48$ & 0.764 \\
\hline GLB (g/L) & $25.88^{\mathrm{b}} \pm 1.09$ & $28.01^{\mathrm{a}} \pm 1.00$ & $27.57^{\mathrm{ab}} \pm 0.43$ & 0.027 \\
\hline $\operatorname{ALB}(g / L)$ & $25.04 \pm 4.00$ & $19.45 \pm 2.54$ & $19.17 \pm 3.66$ & 0.875 \\
\hline $\operatorname{ALP}(\mathrm{U} / \mathrm{L})$ & $90.07 \pm 22.61$ & $113.13 \pm 14.70$ & $116.90 \pm 20.97$ & 0.956 \\
\hline \multicolumn{5}{|c|}{ Serum antioxidant index } \\
\hline MAD (nmol/mL) & $3.49 \pm 0.32$ & $3.26 \pm 0.20$ & $3.32 \pm 0.30$ & 0.624 \\
\hline GSH-Px $(\mathrm{U} / \mathrm{mL})$ & $385.70^{\mathrm{b}} \pm 56.67$ & $465.20^{\mathrm{ab}} \pm 26.90$ & $528.23^{\mathrm{a}} \pm 62.18$ & 0.046 \\
\hline T-AOC (U/mL) & $346.83^{\mathrm{ab}} \pm 29.87$ & $389.73^{\mathrm{a}} \pm 9.83$ & $338.93^{\mathrm{b}} \pm 23.80$ & 0.041 \\
\hline $\mathrm{SOD}(\mathrm{U} / \mathrm{L})$ & $342.33^{\mathrm{a}} \pm 18.00$ & $265.03^{\mathrm{b}} \pm 39.80$ & $272.60^{\mathrm{b}} \pm 13.84$ & 0.038 \\
\hline CAT (U/L) & $88.02^{\mathrm{b}} \pm 5.66$ & $88.11^{\mathrm{b}} \pm 6.26$ & $105.36^{\mathrm{a}} \pm 6.51$ & 0.033 \\
\hline \multicolumn{5}{|c|}{ Serum immunoglobulin index } \\
\hline $\operatorname{IgA}(\mu \mathrm{g} / \mathrm{mL})$ & $947.33^{b} \pm 172.88$ & $1286.67^{b} \pm 264.25$ & $2313.67^{\mathrm{a}} \pm 183.36$ & 0.036 \\
\hline $\operatorname{IgG}(\mathrm{mg} / \mathrm{L})$ & $7422.67^{\mathrm{b}} \pm 386.03$ & $9337.00^{\mathrm{a}} \pm 248.78$ & $9528.00^{\mathrm{a}} \pm 504.55$ & 0.024 \\
\hline $\operatorname{IgM}(\mathrm{mg} / \mathrm{L})$ & $793.33^{c} \pm 97.34$ & $1048.33^{b} \pm 63.61$ & $1326.00^{\mathrm{a}} \pm 156.62$ & 0.029 \\
\hline
\end{tabular}

Note: different lowercase letters in the same row show significant difference $(P<0.05)$.

and Fusobacteria was significantly higher than those in the control group $(P<0.05)$. The proportion of Tenericutes in group II was higher than that in the control.

The top-10 maximum abundance of taxa at the genus level is shown in Figure 2(b). Lactobacillus showed the highest relative abundance in fecal samples. Compared with the control group, the relative abundance of Lactobacillus in groups I and II was decreased, and that of uncul- tured bacteria and of Prevotella-9 showed an increasing trend. Levels of the Prevotellaceae-NK3B31 group and Roseburia in group I were significantly higher than those in the control group. The relative abundance of Megasphaera in group II was significantly higher than that in the control group and in group I $(P<0.05)$. The result indicated that the proportion of bacteria in different groups was different. 


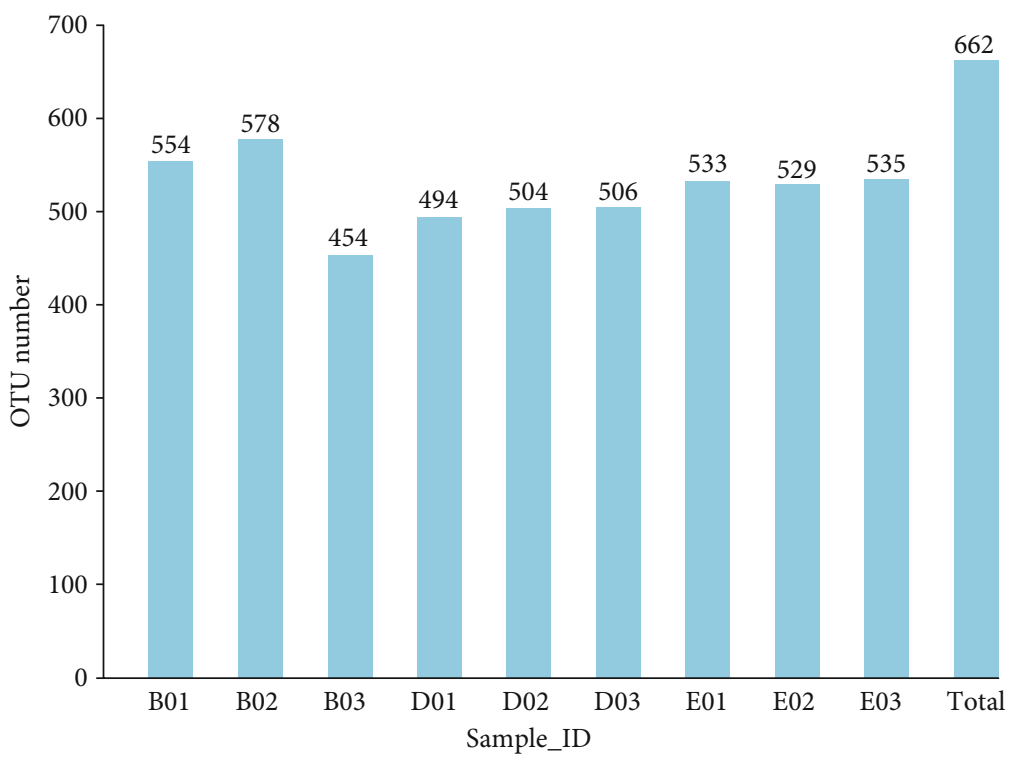

(a)

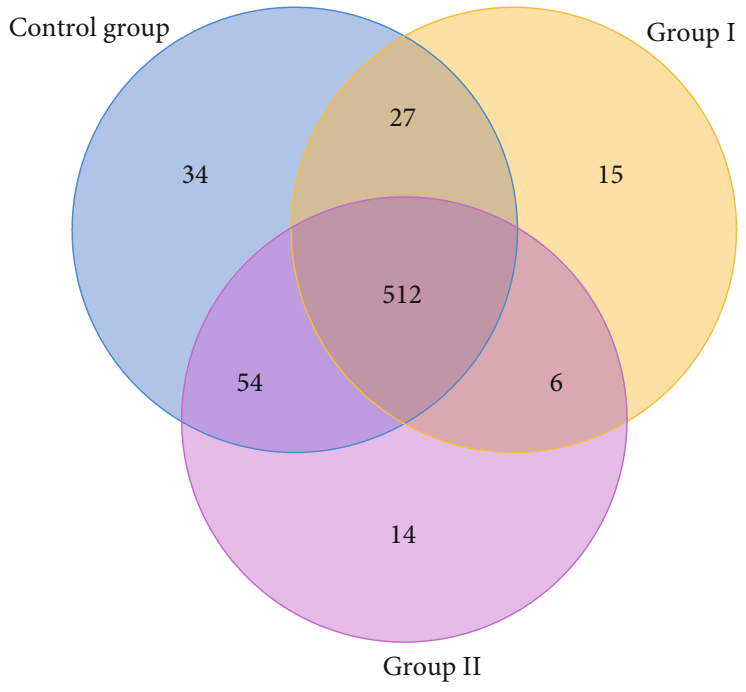

(b)

FIgURE 1: Numbers of OTUs in each sample (a) and a Venn diagram of the OTUs. B01 to E03 indicate the sample ID. Samples B01, B02, and B03 originated from the control group; samples D01, D02, and D03 from group I; and samples E01, E02, and E03 from group II.

3.5. Alpha and Beta Diversity Analyses. Alpha diversity indices, including the observed OTUs, ACE, Chaol, Shannon, Simpson, and coverage for 9 samples, are shown in Table 4. In general, no significant difference in community richness, community diversity, and phylogenetic diversity was observed between the three experimental groups $(P>0.05)$. An unweighted pair group method with an arithmetic mean clustering dendrogram was produced from a fecal sample using a Bray-Curtis distance matrix. As shown in Figure 3(a), the similarity among fecal samples of the control group was higher than that between samples. Nonmetric multidimensional scaling was performed to assess differences between samples. The results showed that, apart from those of the control group, the samples of groups I and II were distinct, indicating that diet composition affected bacterial community composition in feces to some extent.

\section{Discussion}

Broussonetia papyrifera leaf extract contains a large amount of crude protein and is rich in various active compounds such as flavonoids and alkaloids. Since January 1, 2020, in addition to traditional Chinese medicines, the growthpromoting drug feed additives have been completely withdrawn (http://www.moa.gov.cn/govpublic/xmsyj/201909/ t20190909_6327472.htm); thus, B. papyrifera leaf extract may be an invaluable substitute owing to its antibacterial and antiviral properties.

Numerous studies of the effects of plants on animal growth have been conducted, and a previous study showed that extracts of Leucaena leucocephala and Salix babylonica can positively affect production and fermentation of rumen gas, which improves nutrient utilization in lambs [20]. 


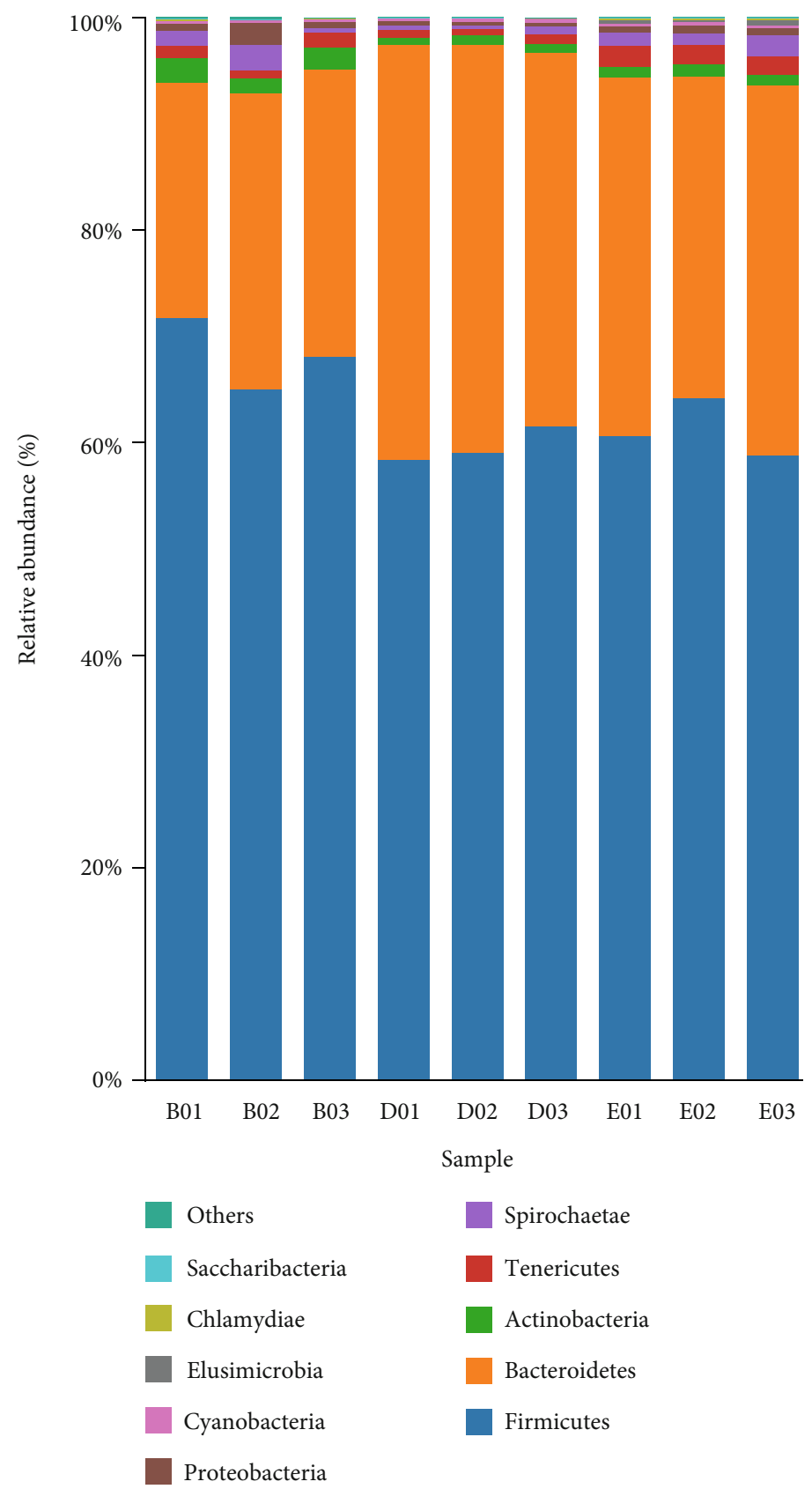

(a)

Figure 2: Continued. 


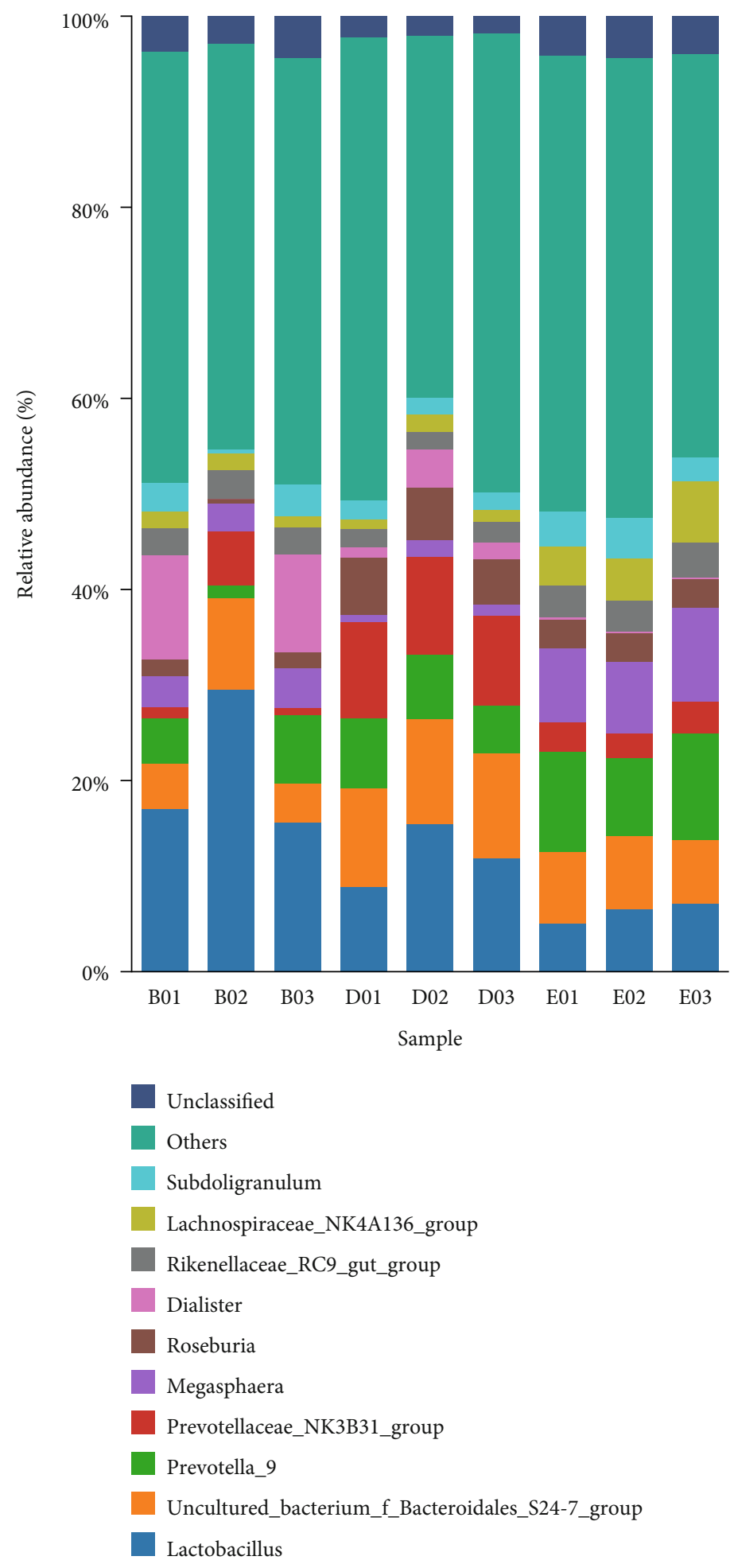

(b)

FIGURE 2: Top-10 maximum abundances of taxa at phylum (a) and genus levels (b).

During the whole experiment, there was little difference in the average weight of the three groups, and there is no significant difference on the 63rd day. This result indicated that the supplementation of the extract of $B$. papyrifera leaves had little effect on the weight of piglets. For weaned piglets, diarrhea seriously affects the healthy development of piglets [21]. Although the addition of the extract had little effect on the weight of piglets, it could significantly reduce the diarrhea rate 
TABle 4: Alpha diversity indices.

\begin{tabular}{|c|c|c|c|c|c|c|}
\hline Samples & OTU & $\mathrm{ACE}$ & Chaol & Simpson & Shannon & Coverage \\
\hline B01 & 554 & 578.2566 & 585.3636 & 0.0321 & 4.5479 & 0.999 \\
\hline B02 & 578 & 598.9752 & 600.5 & 0.0619 & 4.1859 & 0.9991 \\
\hline B03 & 454 & 480.2386 & 483.5625 & 0.0335 & 4.3823 & 0.9991 \\
\hline D01 & 494 & 522.3333 & 530.8333 & 0.0257 & 4.5134 & 0.9988 \\
\hline D02 & 504 & 542.2831 & 554.8333 & 0.0298 & 4.3311 & 0.9988 \\
\hline D03 & 506 & 535.0668 & 546.1818 & 0.0275 & 4.5085 & 0.9989 \\
\hline E01 & 533 & 557.7354 & 564.3333 & 0.0206 & 4.7058 & 0.999 \\
\hline E02 & 529 & 556.5541 & 571.0 & 0.019 & 4.7589 & 0.999 \\
\hline E03 & 535 & 567.5031 & 575.5263 & 0.0248 & 4.5865 & 0.9989 \\
\hline
\end{tabular}

Note: the B01 to E03 represent that the sample IDs B01, B02, and B03 represent the samples from the control group. D01, D02, and D03 represent the samples from group I. E01, E02, and E03 represent the samples from group II.

of piglets, which laid the foundation for the healthy development of piglets and the weight gain in the later stage. Lower feed conversion ratio is also an important performance of $B$. papyrifera additives to improve economic benefits.

Increased ALT concentrations may indicate liver damage [22]. In the present study, ALT concentrations in group I were significantly lower than those in the other two groups, indicating that supplementation with $150 \mathrm{~g} / \mathrm{t}$ leaf extract may be beneficial to the liver of piglets, and the result of the $300 \mathrm{~g} / \mathrm{t}$ treatment was consistent with that of the control group. Therefore, the supplementation treatment had no adverse effects on the piglets' livers. TP in plasma includes ALB and GLB [23]. Increased TP concentrations may cause immune disorders and liver dysfunction-related diseases [24]. However, TP concentrations did not differ between the three groups in the current study, indicating that the supplementation treatment did not adversely affect the piglets' livers. The plasma level of GLU is associated with digestion and the absorption rates of dietary starch, which indicates absorption, transport, and metabolism of sugar. GLU is predominantly important for oxidation and energy supply [25]. A previous study reported that addition of plant extracts can increase GLU levels [26], whereas a different study showed the opposite effect [27]. This may be because of differences in factors including the composition of the plant extract, the amount of supplementation, and the duration of the feeding experiment.

GSH-Px and SOD are important enzymes of the antioxidant system, and their activities are directly proportional to the body's ability to fight against free radicals [28]. MDA is a product of lipid peroxidation in cell membranes, and its concentrations can indirectly reflect the degree of oxidative tissue damage [29]. T-AOC indicates the overall level of enzymes and nonenzymatic antioxidants in the body [30]. CAT is a part of the peroxidation system in animal red blood cells and certain other tissues. Catalyzing the degradation of hydrogen peroxide to water and molecular oxygen is the main function of CAT, which prevents hydrogen peroxide from forming an iron chelate with molecular oxygen. The reaction under the action of the compound produces the toxic $-\mathrm{OH}$ molecule. The body's antioxidant capacity can be assessed using the blood antioxidant index [31]. In the present study, supplementation with $B$. papyrifera extract reduced MDA concentrations in weaned piglets, indicating that this extract inhibits lipid peroxidation of cell membranes, which are beneficial to the body's normal metabolism. In addition to the observed decrease in SOD activity, the activities of GSH-Px, T-AOC, and CAT in the serum of piglets in groups I and II increased. The activity of CAT and GSH-Px in group II was significantly higher than that in the control group. Supplementation with adequate doses of B. papyrifera extract may thus be beneficial to the antioxidant capacity of weaned piglets and promote their growth and development.

Serum Ig levels reflect the current immune status, and Igs play an important role in protecting piglets from invading pathogens which may cause intestinal diseases. In the current study, serum IgA, IgG, and IgM levels were significantly higher in group II than in the control group, and IgG and IgM levels were significantly higher in group II than in group I. A previous study showed that dietary supplementation with Yucca extract can significantly increase the TP content in laying hens [32]. We found that plant extracts can significantly increase serum IgA, IgG, and IgM levels in piglets and improve immunity in weaned piglets which is consistent with the results of a previous study [33]. Therefore, dietary supplementation with $300 \mathrm{~g} / \mathrm{t}$ B. papyrifera extract can significantly improve antioxidant capacity and immune performance in weaned piglets. The level of serum immunoglobulin is only one aspect of immune function. In the future research, we need to do more experiments, such as splenocyte proliferation, natural killer cell activity, and $\mathrm{T}$ cell activity in both the spleen and peripheral blood, in order to obtain a more accurate conclusion of the effect of $B$. papyrifera extract on immune function of piglets.

Microbial community structures in piglet feces and treatment effects were analyzed, and 11 different genera were observed, predominantly belonging to the phyla Firmicutes, Bacteroidetes, Actinobacteria, Tenericumes, Spirochaetae, and Elusimicrobia. These 11 genera are important for degradation or crystallization and conversion of nitrogenous substances. Lactobacillus is a probiotic in animals, and it is important for healthy growth and 


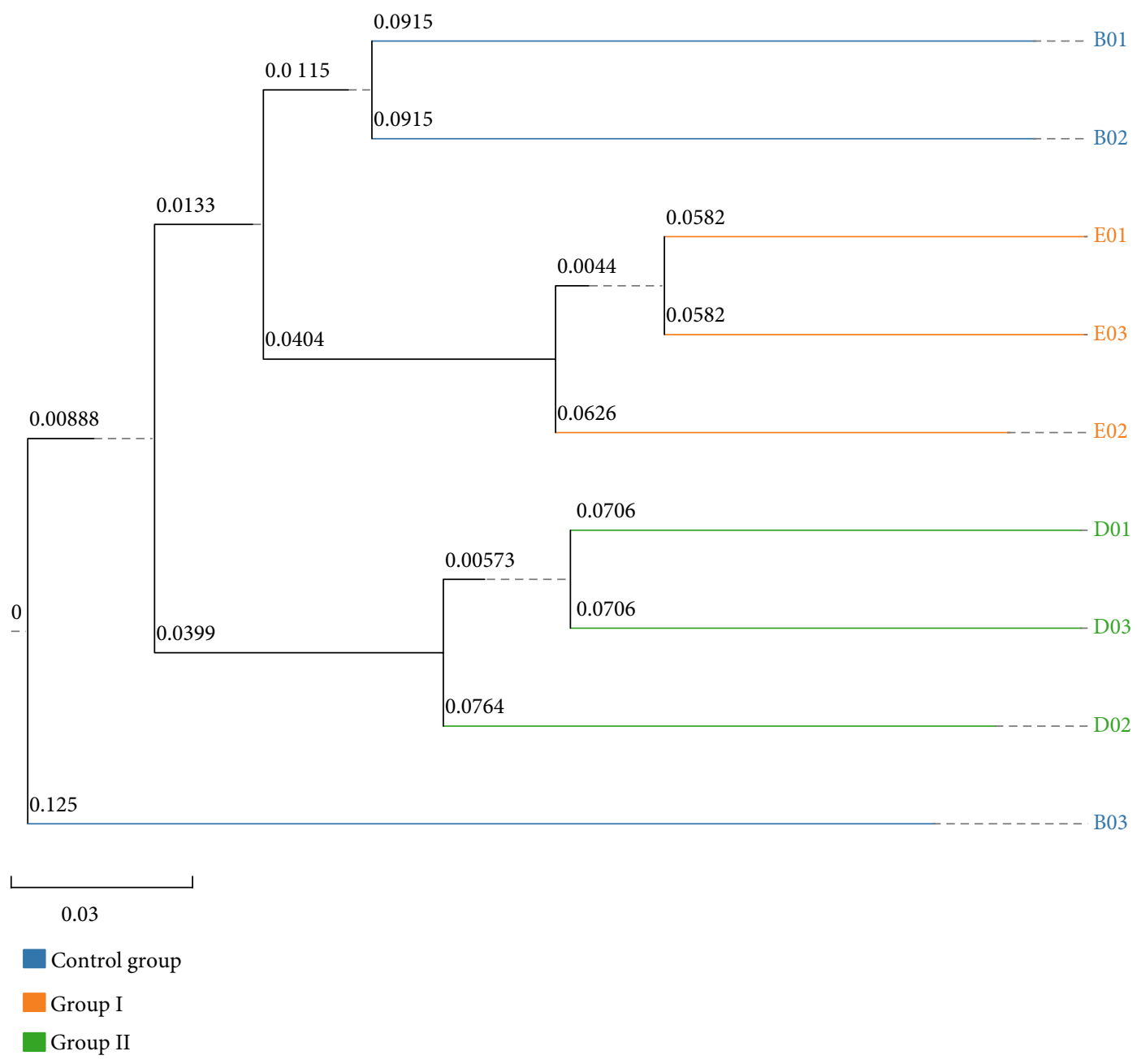

(a)

Figure 3: Continued. 


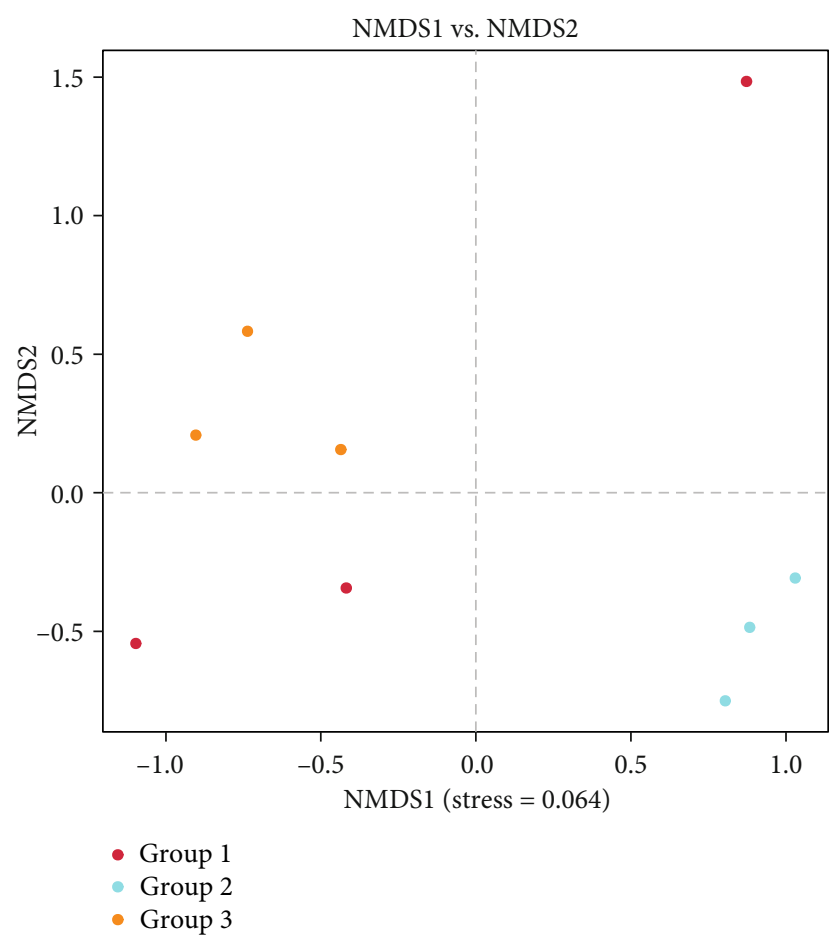

(b)

FIgURe 3: UPGMA cluster analysis (a) and nonmetric multidimensional scaling analysis (b) of piglet fecal samples.

development of the body [34]. Bacteria assigned as "uncultured bacterium" of the Bacteroidales family S24-7 were the predominant taxon in the fecal microflora at the genus level. These bacteria occur in the intestines. In the present study, the proportions of the phyla Firmicutes and Proteobacteria decreased, and those of Bacteroidetes and Fusobacteria significantly increased in groups I and II than those in the control group $(P<0.05)$. The proportion of Tenericutes in the fecal flora of group II was increased. At the genus level, the proportion of Lactobacillus in groups I and II decreased and that of "uncultured bacterium" and Prevotella-9 increased compared with those in the control group. The abundance of PrevotellaceaeNK3B31 group and Roseburia was significantly higher in group I than in the control group and in group II $(P<0.05)$. Roseburia is a common genus of Clostridium cluster XIVa within Firmicutes that harbour prevalent butyrate producers [35]. Metabolism of dietary glycans is pivotal in shaping the human gut microbiota. Roseburia intestinalis as an abundant butyrate-producing Firmicutes plays a great role in the degradation of the major dietary fibre xylan [36]. The proportion of Megasphaera was significantly higher in group II than in the control group and in group I $(P<0.05)$. Macroglobular are Gramnegative cocci that are strictly anaerobic. They can ferment lactose and fruit acid in the gut. A study has reported that Megasphaera is significantly positively correlated with short-chain fatty acid (SCFA) production [37]. Among the SCFAs, propionate and butyrate are most often considered to benefit human health [38]. In the present study, diet composition altered bacterial community structures in piglet feces to some extent, and the proportion of different bacteria may affect the health of piglets. In conclusion, dietary supplementation with $B$. papyrifera leaf extract at an adequate dosage can significantly promote growth performance and antioxidant capacity in weaned piglets. Moreover, this treatment may effectively reduce the occurrence of diarrhea and improve immune functions and disease resistance.

\section{Data Availability}

The data used to support the findings of this study are available from the corresponding author upon request.

\section{Ethical Approval}

The animal procedures used in this study were reviewed and approved by the Gansu Agricultural University's Academic Committee and the National Natural Science Foundation of China according to guidelines established by the Biological Studies Animal Care and Use Committee of Gansu Province (Approval No. 31660670).

\section{Conflicts of Interest}

The authors declare that they have no conflicts of interest.

\section{Authors' Contributions}

Conception and design of the research were by GC; acquisition of data were by SS and MC; analysis and interpretation 
of data were by YS and HW; statistical analysis was by XS and DW; obtaining funding was by GC; drafting the manuscript was by SS; revision of manuscript for important intellectual content was by YS and YY. All authors read and approved the final manuscript.

\section{Acknowledgments}

This work was supported by the fund of College of Animal Science and Technology, Gansu Agricultural University (grant number GAU-XKJS-2018-045).

\section{Supplementary Materials}

Supplementary 1. Sample sequencing data processing results. Supplementary 2. Number of effective sequences and number of OTUs in fecal samples. (Supplementary materials)

\section{References}

[1] T. Richter, P. Braun, and K. Fehlhaber, "Influence of spiced feed additives on taste of hen's eggs," Berliner Und Münchener Tierärztliche Wochenschrift, vol. 115, no. 5-6, pp. 200-202, 2002.

[2] A. A. Woldemariam, Nutritional and anti-nutritional quality of range vegetation in Southern Ethiopia and supplementary values of selected browse leaves to goats, Norwegian University of Life Sciences, Ås, Norway, 2010.

[3] W. S. Darwish, E. A. Eldaly, M. T. El-Abbasy, Y. Ikenaka, S. Nakayama, and M. Ishizuka, "Antibiotic residues in food: the African scenario," Japanese Journal of Veterinary Research, vol. 61, no. 5, pp. S13-S22, 2013.

[4] European Commission, Ban on antibiotics as growth promoters in animal feed enters into effect, Press Release Database, 2005, http://europa.eu/rapid/press-release_IP-05-1687_en .htm.

[5] M. M. Cowan, "Plant products as antimicrobial agents," Clinical microbiology reviews, pp. 491-499, 1999.

[6] S. E. Ilsley, H. M. Miller, H. M. R. Greathead, and C. Kamel, "Plant extracts as supplements for lactating sows: effects on piglet performance, sow food intake and diet digestibility," Animal Science, vol. 77, no. 2, pp. 247-254, 2003.

[7] A. Fejerčáková, J. Vašková, M. Bača et al., "Effect of dietary microbially produced gamma-linolenic acid and plant extracts on enzymatic and non-enzymatic antioxidants in various broiler chicken organs," Journal of Animal Physiology and Animal Nutrition, vol. 98, no. 5, pp. 860-866, 2015.

[8] J. González-Lorca, A. Rivera-Hutinel, X. Moncada, S. Lobos, D. Seelenfreund, and A. Seelenfreund, "Ancient and modern introduction of Broussonetia papyrifera ([L.] Vent.; Moraceae) into the Pacific: genetic, geographical and historical evidence," New Zealand Journal of Botany, vol. 53, no. 2, pp. 75-89, 2015.

[9] E. J. Park and J. M. Pezzuto, "Botanicals in cancer chemoprevention," Cancer \& Metastasis Reviews, vol. 21, no. 3/4, pp. 231-255, 2002.

[10] L. U. Qing-Hua, L. U. Jun, and J. I. Xiang, "Screening of 3 ligindegrading strains and study on their degradation of papermulberry (Broussonetia papyrifera)," Plant Diseases and Pests, vol. 2, no. 5, pp. 55-58, 2011.

[11] H. Tao, B. Si, W. Xu, Y. Tu, and Q. Diao, "Effect of Broussonetia papyrifera L. silage on blood biochemical parameters, growth performance, meat amino acids and fatty acids compositions in beef cattle," Asian-Australasian Journal of Animal Sciences, vol. 33, no. 5, pp. 732-741, 2020.

[12] Y. M. Ma, Z. W. Zhang, and C. L. Feng, "Flavonoids of Broussonetia papyrifera," Chemistry of Natural Compounds, vol. 45, no. 6, pp. 881-882, 2009.

[13] S.-Q. Pang, G.-Q. Wang, J.-s. Lin, Y. Diao, and R.-a. Xu, "Cytotoxic activity of the alkaloids fromBroussonetia papyriferafruits," Pharmaceutical Biology, vol. 52, no. 10, pp. 13151319, 2014.

[14] A. M. Forbes, "Synthesis and biological testing of flavonol analogs in plant germination and cell proliferation," in Dissertations \& Theses - Gradworks, Washington State University, 2009.

[15] V. C. George, G. Dellaire, and H. P. V. Rupasinghe, "Plant flavonoids in cancer chemoprevention: role in genome stability," Journal of Nutritional Biochemistry, vol. 45, pp. 114, 2017.

[16] Z. Chen, S. Zheng, L. Li, and H. Jiang, "Metabolism of flavonoids in human: a comprehensive review," Current Drug Metabolism, vol. 15, no. 1, pp. 48-61, 2014.

[17] M. Naeem, T. Aftab, A. A. Ansari et al., "Radiolytically degraded sodium alginate enhances plant growth, physiological activities and alkaloids production inCatharanthus roseusL," Journal of Radiation Research and Applied Sciences, vol. 8, no. 4, pp. 606-616, 2019.

[18] S. R. Hashemi and H. Davoodi, "Herbal plants and their derivatives as growth and health promoters in animal nutrition," Veterinary Research Communications, vol. 35, no. 3, pp. 169180, 2011.

[19] J. Yu, Y. Song, B. Yu et al., “Tannic acid prevents post-weaning diarrhea by improving intestinal barrier integrity and function in weaned piglets," Journal of Animal Science and Biotechnology, vol. 11, no. 1, 2020.

[20] F. S. Jiménez-Peralta, A. Z. M. Salem, P. Mejia-Hernández et al., "Influence of individual and mixed extracts of two tree species on in vitro gas production kinetics of highconcentrate diet fed to growing lambs," Livestock Science, vol. 136, no. 2-3, pp. 192-200, 2011.

[21] K.-H. Lin and Y.-H. Yu, "Evaluation of Bacillus licheniformisFermented Feed Additive as an Antibiotic Substitute: Effect on the Growth Performance, Diarrhea Incidence, and Cecal Microbiota in Weaning Piglets," Animals, vol. 10, no. 9, p. $1649,2020$.

[22] T. Stokol and H. Erb, "The Apo-enzyme Content of Aminotransferases in Healthy and Diseased Domestic Animals," Veterinary Clinical Pathology, vol. 27, no. 3, pp. 71-78, 1998.

[23] J. Riahi, B. Amri, F. Chibani et al., "Comparative analyses of albumin/globulin grain proteome fraction in differentially salt-tolerant Tunisian barley landraces reveals genotype-specific and defined abundant proteins," Plant Biology, vol. 21, no. 4, pp. 652-661, 2019.

[24] A. S. Kansal, S. Trikha, A. Sharma, and S. Sshai, "Diagnostic utility of serum ascites albumin gradient against ascitic fluid total protein for detection of liver disease in patients of ascitesa comparative study," International Journal of Medical Research and Review, vol. 12, pp. 861-865, 2015.

[25] M. E. Krass and F. S. LaBella, "Biochemical evidence for a secretory role of the pineal body. Oxidation of [1-14C]- and [6-14c]glucose in vitro by pineal body, pituitary, and brain 
from young and adult animals," Journal of Neurochemistry, vol. 13 , no. 11 , p. $6,2010$.

[26] G. Henry, "Plants and plant extracts for improving animal productivity," The Proceedings of the Nutrition Society, vol. 62, no. 2, pp. 279-290, 2003.

[27] I. N. Okafor and C. E. Dioka, "Effect of momordica charantia extracts on blood glucose and lipid peroxidation levels in albino rats," Tropical Journal of Medical Research, vol. 14, no. 1, 2011.

[28] Y. Yang, S. Chen, and J. Zhang, "The updated role of oxidative stress in subarachnoid hemorrhage," Current Drug Delivery, vol. 13, no. 999, 2017.

[29] M. S. Sitorus, D. R. Anggraini, and Hidayat, "Decreasing Free Radicals Level on High Risk Person After Vitamin C and E Supplement Treatment," IOP Conference Series: Materials Science and Engineering, vol. 180, p. 012093, 2017.

[30] Y. T. Cui, B. Liu, J. Xie, P. Xu, H. M. Habte-Tsion, and Y. Y. Zhang, "The effect of emodin on cytotoxicity, apoptosis and antioxidant capacity in the hepatic cells of grass carp (Ctenopharyngodon idellus)," Fish \& Shellfish Immunology, vol. 38, no. 1, pp. 74-79, 2014.

[31] M. S. Mansuri, S. D. Jadeja, M. Singh, N. C. Laddha, M. Dwivedi, and R. Begum, "The catalase gene promoter and 5-untranslated region variants lead to altered gene expression and enzyme activity in vitiligo," British Journal of Dermatology, vol. 177, no. 6, pp. 1590-1600, 2017.

[32] S. Jia, L. Ren, J. Liang et al., "Effect of yucca extract on production performance and egg quality of laying hens," China Poultry, 2014.

[33] F. Wu, P. L. Li, L. L. Bai et al., "Responses in colostrum production and immunoglobulin concentrations to conjugated linoleic acid fed to multiparous sows during late gestation," Animal Feed Science and Technology, vol. 210, pp. 200-208, 2015.

[34] C. Zhang, J. Zhang, W. Fan, M. Huang, and M. Liu, "Effects of dietaryLactobacillus delbrueckiion growth performance, body composition, digestive and absorptive capacity, and gene expression of common carp (Cyprinus carpioHuanghe var)," Aquaculture Nutrition, vol. 25, no. 1, pp. 166-175, 2019.

[35] S. H. Duncan, G. L. Hold, A. Barcenilla, C. S. Stewart, and H. J. Flint, "Roseburia intestinalis sp. nov., a novel saccharolytic, butyrate-producing bacterium from human faeces," International Journal of Systematic and Evolutionary Microbiology, vol. 52, no. 5, pp. 1615-1620, 2002.

[36] M. L. Leth, M. Ejby, C. Workman et al., "Differential bacterial capture and transport preferences facilitate co-growth on dietary xylan in the human gut," Nature Microbiology, vol. 3, no. 5, pp. 570-580, 2018.

[37] C. Long, C. Rösch, S. de Vries, H. Schols, and K. Venema, “Cellulase and alkaline treatment improve intestinal microbial degradation of recalcitrant fibers of rapeseed meal in pigs," Journal of Agricultural and Food Chemistry, vol. 68, no. 39, pp. 11011-11025, 2020.

[38] A. Mukherjee, C. Lordan, R. P. Ross, and P. D. Cotter, "Gut microbes from the phylogenetically diverse genusEubacteriumand their various contributions to gut health," Gut Microbes, vol. 12, no. 1, p. 1802866, 2020. 